\title{
In Vitro antibacterial activity of rumex nervosus, plantago lanceolata, solanum incanum and lepidium sativum against selected bacterial pathogens of human and animals
}

\author{
Endalkachew Abebe ${ }^{1}$ and Negesse Mekonnen ${ }^{2^{*}}$ \\ ${ }^{1,2}$ College of Veterinary Medicine, Haramaya University, P. O. Box 138, Dire Dawa, Ethiopia. \\ ${ }^{*}$ Corresponding Author: College of Veterinary Medicine, Haramaya University, P. O. Box 138, \\ Dire Dawa, Ethiopia, Email: mnegesse@yahoo.com
}

http://dx.doi.org/10.4314/evj.v20i2.9

\begin{abstract}
Medicinal plants are used as a primary means of tackling different ailments especially in developing countries. In the present study, the leaves of Rumex nervosus, Plantago lanceolata, Lepidium sativum and Solanum incanum were collected and extracted by maceration method using 70\% methanol. The extracts were concentrated and the yields recorded. Antibacterial effects of the extracts were tested on selected bacteria such as Streptococcus, S. aureus, L. monocytogenes, E. coli, and Salmonella which were obtained from Haramaya University, Veterinary Microbiology Laboratory. Preliminary screening test for the extract was made using agar disc diffusion method and subsequently the minimum inhibitory concentration (MIC) and minimum bactericidal concentration (MBC) were determined by agar dilution assay based on the zone of bacterial growth inhibition. The finding indicated that Rumex nervosus showed have the highest zone of inhibition $(20 \mathrm{~mm})$ against the genus Salmonella followed by Plantago lanceolata with the zone of inhibition (16mm) against L. monocytogenes. On the other hand, Lepidium sativum and Solanum incanum did not have any antibacterial activity against all the cultured bacteria. The minimum inhibitory concentration and the minimum bactericidal concentration of Rumex nervosus against $S$. aureus were $1.56 \times 10^{3} \mu \mathrm{g} / \mathrm{ml}$ and that of Plantago lanceolata against L. monocytogenes were $6.25 \times 10^{3} \mu \mathrm{g} / \mathrm{ml}$ and $1.25 \times 10^{4} \mu \mathrm{g} / \mathrm{ml}$, respectively. From the findings it can be concluded that Rumex nervosus and Plantago lanceolata have shown to be a better antibacterial activity against selected bacterial pathogens, while leave extracts of other medicinal plants do not have any effect. Fractionated components of the plants might show better effect which needs further investigation using different solvent and standard medium.
\end{abstract}


Keywords: Agar disc diffusion, Antibacterial activity, Rumex nervosus, Plantago lanceolata, Solanum incanum, Lepidium sativum

\section{Introduction}

Since the beginning of human civilization medicinal plants have been used by mankind for their therapeutic values. Many infectious diseases have been known to be treated with herbal remedies throughout the history of mankind. Recent review indicated that more than $80 \%$ of the world's population relied on traditional medicine for their primary healthcare needs (Ekor, 2014). In Ethiopia $90 \%$ of the population still rely on herbal medicine (Payyappa llimana, 2009).

Medicinal plants are the sources of bioactive compounds used mainly for medicinal purposes. In recent years human pathogenic microorganisms have developed resistance in response to the indiscriminate use of commercial used antimicrobial drugs commonly employed in the treatment of infectious diseases. This situation, the undesirable side effect of certain antibiotics and the emergence of previously uncommon infections have forced scientists to look for a new antimicrobials. Infectious diseases are still the leading cause of death worldwide. Antibiotic resistance has become a global concern. The clinical efficacy of many existing antibiotics is being threatened by the emergence of multidrug resistant pathogen (Carlet et al., 2012).

Herbal medicines are in great demand both in developed and developing countries as a source of primary health care owing to their attributes having wide biological and medicinal activities, high safety margins and lesser costs. Herbal molecules are safe and would overcome resistance produced by the pathogens as they exist in a combined form or in a pooled form of more than one molecule in the protoplasm of the plant cell (Lai and Roy, 2004; Tapsell et al., 2006).

Locally, these plants were used for the treatment of different ailments by traditional healers of which Solanum incanum was used for the treatment of geranamaalatu manifested by immobility and curved back, Rumex nervosus was used for the treatment of qebena manifested by shivering, headache, back pain, fever, blood coagulation and thrust, Plantago lanceolata was used for the treatment of meda manifested by accidental injury and Lepidium sativum was 
used for the treatment of Qufa manifested by headache, dry cough and fever. The preliminary antibacterial activities of leaves of these plants were described by different researchers for instance the antibacterial effect of Rumex nervosus by Kasimala et al. (2014), Solanum incanum by Indhumathi and Mohandass (2014), Plantago lanceolata by Ferrazzano et al. (2015) and Lepidium sativum by Adam et al. (2011). Therefore, the objectives of the present study are to evaluate the antimicrobial activity of these plants against five pathogenic bacteria of human and veterinary importance.

\section{Materials and Methods}

\section{Study area and experimental design}

Plants were collected from Haramaya University compound and Bati (a small village near to Haramaya University). After collection identification of the plants was done and voucher number was provided by Haramaya University herbarium. Agroecologically, the area is dominantly highland consisting of undulating landscape, hills and some mountains with gorges and plain areas. The vegetation includes bush and shrubs covering small areas and scattered trees such as eucalyptus and acacia. The soil type is dominantly sandy loam with pocket areas of clay loam. The area has bimodal characteristics with two rainy seasons, the long rainy season (mid-June to mid-September) and the short rainy season (from mid-February to mid-May). The average annual rainfall of the area ranges from 700 to $900 \mathrm{~mm}$. The mean annual temperature of the area is $18^{\circ} \mathrm{C}$ in high land and $22^{\circ} \mathrm{C}$ in the low lands. 


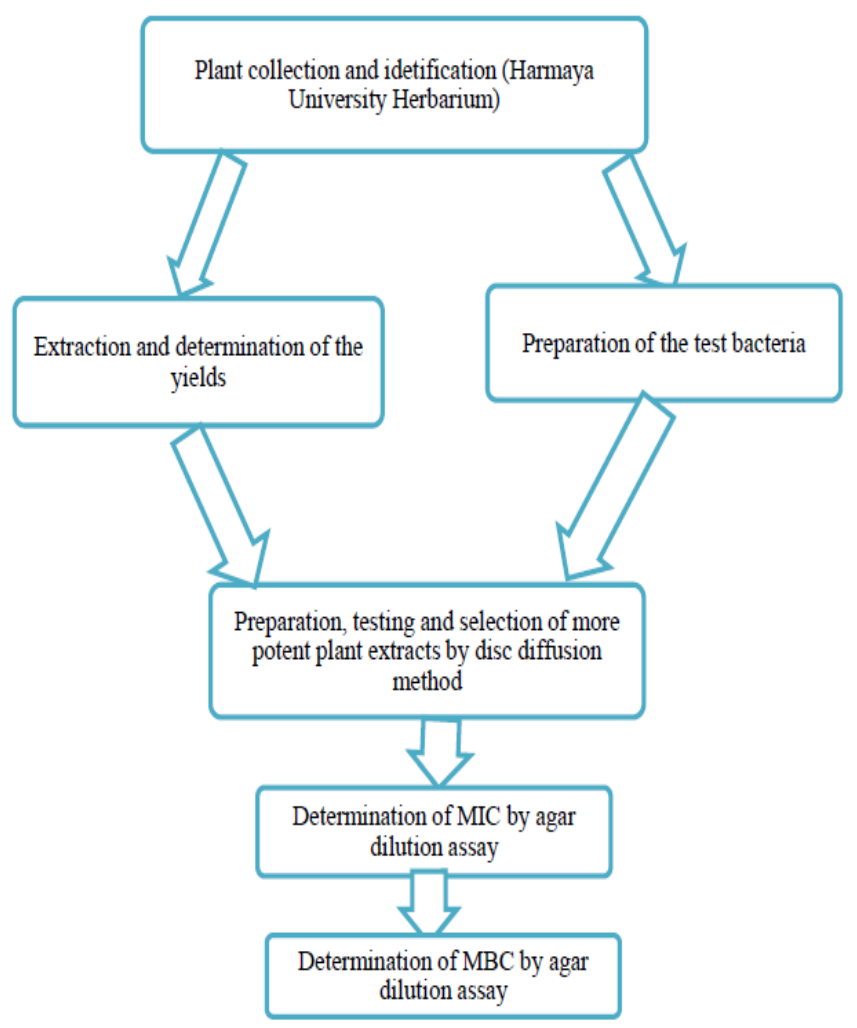

Figure 1: Schematic representation of the design of the experiment

\section{Plant collection and extraction technique}

The plants were selected based on the information given by the traditional healers in the area. Enough amounts of leaves were harvested on fully developed green stages of the plants in a year 2013/14. After collection the plant materials were identified by taxonomist at Haramaya University. Fresh plant leaves were washed under running tap water, air dried and chopped to fine piece that could be weighed. Drying was held in an airy place at ambient temperature away from direct sunlight. After the leaves were dry enough to break, the plants were ground to fine powder in a blender and stored in clean stopper bottles. The dried plant powder from each plant was extracted with $70 \%$ methanol by maceration method of extraction with frequent agitation on a 
shaker and the resulting supernatant was filtered using filter paper (Whatman No.1) with particle size of $11 \mu \mathrm{m}$.

The process of extraction was repeated three times and the filtrates of all portions were collected in one vessel. The filtrate was then concentrated through rotary evaporation (Buchi Rotary Evaporator, R-210) at $40^{\circ} \mathrm{c}$. The residue was then placed in water bath at $40^{\circ} \mathrm{C}$. The resulting dried mass was weighed as a percentage yield and packed into a glass vial and stored in desiccators over silica gel until use (Goyal et al., 2008).

\section{Antibacterial sensitivity testing}

The antibacterial activity of $70 \%$ methanol extract was evaluated step by steps and all the four extracts were screened by agar disc diffusion against five bacteria. Those plants having superior antibacterial activity were further evaluated for MIC and MBC by agar dilution assay.

\section{Preparation of test microorganisms}

Isolates of five bacteria Staphylococcus aureus, Streptococcus, Listeria monocytogen, E. coli and Salmonella were obtained from Haramaya University, veterinary microbiology laboratory. Pure cultures of the isolates were sub cultured and prepared for in vitro antimicrobial activity test using Muller Hinton agar.

\section{Preparation of the discs}

Each of the discs was cut from Whatman No.1 filter paper with an approximate diameter of $6 \mathrm{~mm}$. The disc were sterilized by autoclaving at $121^{\circ} \mathrm{C}$ for 15 minutes and impregnated with the extract by soaking in 10\% extract solution for 2 hours. With the help of sterilized forceps, each disc was recovered from the extract and held for 20-30 seconds for some of the methanol to evaporate before being applied aseptically onto the agar surface in a plate which had initially been inoculated with a pure culture of the test organism (Alo et al., 2012). 


\title{
Determination of antimicrobial activity of the extracts
}

\author{
Agar disc diffusion assay
}

Sterile Muller Hilton agar medium was prepared according to Murray et al. (1983) and dispensed into a petridish plates. The microbial suspensions were prepared by comparing with Mc-Farland turbidity standard of $0.5 \times 10^{8} \mathrm{CFU} /$ $\mathrm{ml}$. The microbial suspensions were streaked over the surface of the Muller Hilton agar using a sterile cotton swab in order to get a uniform microbial growth on both control and test plates. Under aseptic conditions the discs were placed on the agar plates. chloramphenicol and sterile saline discs were placed as positive and negative control, respectively. The inoculated plates were then incubated at $37^{\circ} \mathrm{C}$ for 24 hours. The diameter of microbial inhibition zones (mm) were measured and recorded (Joshua et al., 2102).

\section{Agar dilution assay}

According to Parekh et al. (2006) agar disc diffusion did not determine the minimum inhibitory concentration (MIC) rather used for preliminary screening. Those plant extracts having inhibition zone greater than or equals to $12 \mathrm{~mm}$ in diameter in disc diffusion assay were further screened by agar dilution assay. The extent of antimicrobial activity of the crude extracts based on inhibition zone diameter has been described as low (12-18 mm), moderate (19-22 mm) and strong (23-38 mm) activity (Ahmad et al., 1999). However, evaluation of the antibacterial activity of plant extracts only by agar diffusion method is not sufficient, rather it is necessary to quantify or determine the MIC and MBC using agar dilution assay.

\section{Minimum Inhibitory Concentration (MIC)}

Minimum inhibitory concentration is defined as the highest dilution or least concentration of the extracts that inhibit growth of organisms. Determination of MIC is the crucial steps to detect the presence or absence of antimicrobial activity from medicinal plants. One gram of each extract was dissolved in $9 \mathrm{ml}$ of physiological saline solution and this was used as a stock solution. Two fold serial dilutions were prepared by mixing with the Muller Hinton agar. Therefore, $10 \%, 5 \%, 2.5 \%, 1.25 \%, 0.625 \%, 0.313 \%, 0.156 \%$ and $0.078 \%$ concentrations were prepared and allowed to solidify. The bacterial suspension 
prepared by comparing with Mc-Farland turbidity standard $\left(0.5 \times 10^{8} \mathrm{CFU} / \mathrm{ml}\right)$ was streaked on the above petridishes starting from the lower concentration. All petridishes were incubated at $37^{\circ} \mathrm{c}$ for 24 hours and then MIC was determined (Ferrazzano et al., 2015).

\section{The minimal bactericidal concentration $(M B C)$}

The minimal bactericidal concentration which is the confirmatory test was determined by re-inoculation of each of the inhibited media on the extract free Muller Hinton agar media separately. The inoculated media was incubated at $37^{\circ} \mathrm{C}$ for 24 hours. Absence of visible growth of bacterial colony after 24 hours indicated bactericidal activity. The lowest concentration of the test extract that prevented visible growth of bacterial colony was considered to be MBC (Jorgensen and Ferraro, 2009; Mukesh and Smita, 2010).

\section{Results}

\section{Yield of extracts}

The yields of the extracts were indicated in table 1, the highest yield was from Rumex nervosus and the lowest yield was from Solanum incanum (10\%).

Table 1: The yields of $70 \%$ methanol extracts of four medicinal plants

\begin{tabular}{lccccc}
\hline $\begin{array}{l}\text { Scientific name of } \\
\text { the plants }\end{array}$ & $\begin{array}{c}\text { local name } \\
\text { of the plants }\end{array}$ & $\begin{array}{c}\text { Part of the } \\
\text { plant used }\end{array}$ & Yields & $\begin{array}{c}\text { Voucher } \\
\text { number }\end{array}$ & $\begin{array}{c}\text { Growth } \\
\text { forms }\end{array}$ \\
\hline Lepidium sativum & Shifu & Leaf & $11 \%$ & 014534 & Herb \\
Solanum incanum & Hidi & Leaf & $10 \%$ & 015593 & Shrub \\
Rumex nervosus & Dhengego & Leaf & $21 \%$ & 022321 & Shrub \\
Plantago lanceolata & Feyissa & Leaf & $12.8 \%$ & 005621 & Herb \\
\hline
\end{tabular}

\section{Disc diffusion assay}

The antibacterial activity of the extracts was evaluated by the presence or absence of inhibition zone and by measuring the diameter of the inhibition zone around the discs (Table 2). 
Table 2: Agar disc diffusion assay of four medicinal plants against five bacterial pathogens

\begin{tabular}{|c|c|c|c|c|c|}
\hline \multirow[t]{2}{*}{ Plant extract } & \multicolumn{5}{|c|}{ Test Bacteria } \\
\hline & S. aureus & Streptococcus & $\begin{array}{c}\text { L. } \\
\text { monocytogenes }\end{array}$ & $\begin{array}{l}\text { E. } \\
\text { coli }\end{array}$ & Salmonella \\
\hline Rumex nervosus & $9 \mathrm{~mm}$ & $9 \mathrm{~mm}$ & $7 \mathrm{~mm}$ & $7 \mathrm{~mm}$ & $20 \mathrm{~mm}$ \\
\hline $\begin{array}{l}\text { Plantago } \\
\text { lanceolata }\end{array}$ & $8 \mathrm{~mm}$ & $9 \mathrm{~mm}$ & $16 \mathrm{~mm}$ & $6 \mathrm{~mm}$ & $7 \mathrm{~mm}$ \\
\hline $\begin{array}{l}\text { Solanum } \\
\text { incanum }\end{array}$ & $6 \mathrm{~mm}$ & $6 \mathrm{~mm}$ & $7 \mathrm{~mm}$ & $7 \mathrm{~mm}$ & $6 \mathrm{~mm}$ \\
\hline $\begin{array}{l}\text { Lepidium } \\
\text { sativum }\end{array}$ & $6 \mathrm{~mm}$ & $6 \mathrm{~mm}$ & $6 \mathrm{~mm}$ & $7 \mathrm{~mm}$ & $6 \mathrm{~mm}$ \\
\hline Chloramphenicol & $20 \mathrm{~mm}$ & $21 \mathrm{~mm}$ & $17 \mathrm{~mm}$ & $\begin{array}{c}19 \\
\mathrm{~mm}\end{array}$ & $23 \mathrm{~mm}$ \\
\hline Saline & $0 \mathrm{~mm}$ & $0 \mathrm{~mm}$ & $0 \mathrm{~mm}$ & $0 \mathrm{~mm}$ & $0 \mathrm{~mm}$ \\
\hline
\end{tabular}

\section{MIC and MBC of medicinal plants using agar dilution assay}

In the present study those plant extracts with zone of inhibition greater than $12 \mathrm{~mm}$ in diameter in at least one of the bacteria were further evaluated for the determination of MIC (Table 3) and MBC (Table 4).

Table 3: MIC value of medicinal plants in $\mu \mathrm{g} / \mathrm{ml}$

\begin{tabular}{lccc}
\hline Plant extracts & S. aureus & L. monocytogenes & Salmonella \\
\hline Rumex nervosus & $1.56 \times 10^{3}$ & NA & $2.5 \times 10^{4}$ \\
Plantago lanceolata & $\mathrm{NA}$ & $6.25 \times 10^{3}$ & $\mathrm{NA}$ \\
\hline
\end{tabular}

$\mathrm{NA}=$ not done since the zone of inhibition is less than $12 \mathrm{~mm}$ in diameter

Table 4: MBC value of medicinal plants in $\mu \mathrm{g} / \mathrm{ml}$

\begin{tabular}{lccc}
\hline Plant extracts & S. aureus & L. monocytogenes & Salmonella \\
\hline Rumex nervosus & $1.56 \times 10^{3}$ & $\mathrm{NA}$ & $5 \times 10^{4}$ \\
Plantago lanceolata & $\mathrm{NA}$ & $1.25 \times 10^{4}$ & $\mathrm{NA}$ \\
\hline
\end{tabular}

$\mathrm{NA}=$ not done since the zone of inhibition is less than $12 \mathrm{~mm}$ in diameter

\section{Discussion}

In present study the highest extraction yield was recorded from Rumex nervosus (21\%) followed by Plantago lanceolata. In another study slightly lower yield (17.65\%) was reported with 100\% methanol from Yemen (Al-Naqeb, 
2015). The slight difference might be attributed to the polarity difference in the solvent used in the present work (70\% methanol). The lowest yield was obtained from leaf of Solanum incanum (10\%). Comparable yield of Solanum incanum was reported in another study done in Iran (Khalighi Sigarodi et al., 2012). Generally factors like extraction technique, parts of the plant used, concentration and type of solvent used can greatly affect the yield of extracts.

The extract from Rumex nervosus have a good antibacterial activity against Salmonella $(20 \mathrm{~mm})$ compared to the standard drug chloramphenicol $(23 \mathrm{~mm})$ which showed a strong antibacterial activity whereas the least activity was recorded against E. coli $(7 \mathrm{~mm})$ and Listeria monocytogenes $(7 \mathrm{~mm})$. This finding was similar with the reports from Yemen, where methanol extract of Rumex nervosus had shown antibacterial activity against Salmonella but failed to demonstrate antibacterial activity for $E$. coli (Al-Naqeb, 2015) .A study conducted by Kasimala et al. (2014) on methanol extract of Rumex nervosus had also confirmed the absence of antibacterial activity against E.coli and $S$. aureus. However, opposite results were reported by Abdel-Sattar et al. (2008), where methanol extract of Remux nervosus had shown antibacterial activity against $S$. aureus.

Plantago lanceolata showed antimicrobial activity against Listeria monocytogenes with a zone of inhibition of $16 \mathrm{~mm}$ in diameter which was comparable with the standard drug chloramphenicol $(17 \mathrm{~mm})$. However, Plantago lanceolata failed to demonstrate antibacterial activity against Streptococcus, E.coli, S. aureus and Salmonella. In contrast to the current findings, a concentration of $P$. lanceolata extract between $0.25 \mathrm{mg} / \mathrm{mL}$ and $2.0 \mathrm{mg} / \mathrm{mL}$ had shown an antimicrobial activity against different species of the genus Streptococcus (Ferrazzano et al., 2015). Nevertheless, it appeared that the antibacterial activity of $P$. Lanceolata was not exhaustively studied yet. However, a range of pharmacological properties has been found in tests with $P$. Lanceolata extract including weak antibiotic, wound healing, anti-inflammatory, anti-ulcerogenic, laxative, analgesic, antioxidant and immunomodulatory effect (Schmelzer et al., 2008).

In the current study, Solanum incanum didn't show any antibacterial activity against all pathogens. In another study methanol extracts of Solanum incanum fruit had shown an antibacterial activity against $S$. aureus and $S$. pyogenes with zone of inhibition $25 \mathrm{~mm}$ and $28 \mathrm{~mm}$, respectively. This might be because 
of the part of the plant used. In the present study the leaf of the plant used and it is well-known that the distributions of bioactive compounds differ within the plant parts used (Singh et al., 2015). However, Solanum incanum didn't show any antibacterial activity against $S$. Agalactiae (Owino et al., 2013). A study conducted by Indhumathi and Mohandass (2014) had also shown the antibacterial activity of ethanol extract of Solanum incanum fruit against Staphylococcus aureus and Salmonella paratypi with the zone of inhibition of $24 \mathrm{~mm}$ and $29 \mathrm{~mm}$, respectively.

In this study, the leave of Lepidium sativum did not show any antibacterial activity against all of the five pathogens. However, in another study Lepidium sativum seed methanol extracts had shown antibacterial activity against $S$. aureus and $E$. Coli with the inhibition zone of $15 \mathrm{~mm}$ and $17 \mathrm{~mm}$ in diameter, respectively (Adam et al., 2011). This might be because of the difference in the plant parts used. The present study has shown that some of the plants were potentially rich source of antibacterial agents which had re-assured their importance in traditional remedies.

In this study, the crude extracts of Rumex nervosus and Plantago lanceolata showed better antibacterial activity against some of the pathogens. The remaining two plant extract did not show antibacterial activity against all pathogens tested. The difference might be due to variation in their phytochemical compositions.

Determination of the MIC and MBC were performed for those plant extracts that have shown better antibacterial activity by disc diffusion method with inhibition zone of $>12 \mathrm{~mm}$ in diameter. The MIC of Rumex nervosus for S. aureus and Salmonella were $1.56 \times 10^{3} \mu \mathrm{g} / \mathrm{ml}$ and $25 \times 10^{3} \mu \mathrm{g} / \mathrm{ml}$, respectively; while the $\mathrm{MBC}$ was $1.56 \times 10^{3} \mu \mathrm{g} / \mathrm{ml}$ and $50 \times 10^{3} \mu \mathrm{g} / \mathrm{ml}$, respectively. A study conducted by Al-Asmari et al. (2015) indicated that methanol and hexane leaf extracts of $R$. Nervosus had shown a MBC of $5 \times 10^{4} \mu \mathrm{g} / \mathrm{ml}$ against $S$. aureus. The MIC of $P$. Lanceolata for L. monocytogenes and Salmonella were $6.25 \times 10^{3} \mu \mathrm{g} / \mathrm{ml}$ and 12.5 x $10^{3} \mu \mathrm{g} / \mathrm{ml}$, respectively, while the MBC was $12.5 \times 10^{3} \mu \mathrm{g} / \mathrm{ml}$ and $25 \times 10^{3} \mu \mathrm{g} /$ $\mathrm{ml}$, respectively. Slightly lower MIC and MBC were reported by Ferrazzano et al. (2015) from P. Lanceolata infusion by broth microdilution method against the different species of Streptococcus ranged from $5 \times 10^{2}$ to $1 \times 10^{3} \mu \mathrm{g} / \mathrm{ml}$ and 5 $\mathrm{x} 10^{2}-2 \times 10^{3} \mu \mathrm{g} / \mathrm{ml}$ respectively. It is well documented that inoculum size, type of growth medium, incubation time and inoculum preparation methods were greatly influence of MIC values (Balouiri et al., 2015). 
Broth dilution method is shown to be more sensitive than agar dilution assay, although agar dilution assay is superior for its convenience to determine MIC break point (Jiang et al., 2012). In the present study Mueller Hinton Agar media was used for both disc diffusion and agar dilution assay for MIC and MBC determination due to limited resources. Crude extracts contain many bioactive compounds having different solubility and rate of diffusion and most antimicrobial compounds have intermediate polarity or are non polar requiring broth media to allow easy diffusion of such compounds (Eloff, 2003).

\section{Conclusion}

From these findings, it can be concluded that the crude methanol extracts of Rumex nervosus and Plantago lanceolata have shown proven antibacterial activity against zoonotic bacterial pathogens with different potency. They can provide a candidate lead molecule for the development of new antimicrobial agent. From the present result we recommend further investigation on the fractionated components using different solvent and standard medium for the in vitro test.

\section{Acknowledgements}

The authors would like to thank Haramaya University, College of Veterinary Medicine for financial and logistic support for the study. In addition to these, we are very much grateful to Veterinary Microbiology section for the provision of bacterial isolates.

\section{References}

Abdel-Sattar, E., Harraz, F.M. and El-Gayed S. H., 2008. Antimicrobial Activity of extracts of some plants collected from the kingdom of Saudi Arabia. Med. Sci., 15, 25-33.

Adam, S. I. Y., Salih, S. A. M. and Abdelgadir, W. S., 2011. In vitro antimicrobial assessment of lepidium sativum 1. seeds extracts. Asian J. Med. Sci., 3, 261-266

Ahmad, I, Zaiba-Beg, A.Z. and Mehmood, Z., 1999. Antimicrbial potency of selected medicinal plant with special interest in activity against phytopathogenic fungi. Indian Vet. Med. J., 23, 01-08.

Ethiop. Vet. J., 2016, 20 (2), 119-131 
Al-Asmari, A. K., Siddiqui, Y. M., Athar., M. d. T., Al-Buraidi, M., Al-Eid, A. S. and Horaib, G. B., 2015. Antimicrobial activity of aqueous and organic extracts of a Saudi medicinal plant: Rumexnervosus. J. Pharm. Bioall Sci., 7, 300-303.

Al-Naqeb, G., 2015. Antioxidant and antibacterial activities of some Yemeni medicinal plants. Int. J. Herb. Med., 3, 06-11.

Alo, M. N., Anyim, C., Igwe, J. C., Elom, M. and Uchenna, D.S., 2012. Antibacterial activity of water, ethanol and methanol extracts of Ocimumgratissimum, Vernoniaamygdalina and Aframomummelegueta. Adv. Appl. Sci. Res., 3, 844-848.

Balouiri, M., Sadiki, M. and Ibnsouda, S. K., 2015. Methods for in vitro evaluating antimicrobial activity. J. Pharm. Anal., 6, 71-79.

Carlet, J., Jarlier, V., Harbarth, S., Voss, A., Goossens, H. and Pittet, D., 2012. Ready for a world without antibiotics. The pensieres antibiotic resistance calls to action. Antimicrob. Resist. Infect. Control., 1,11.

Ekor, M., 2014. The growing use of herbal medicine: Issues related to adverse reactions and challenges in monitoring safety. Front. Pharmacol., 4, 1-10.

Eloff, J.N., 2003. Antibacterial assays of plant extracts by agar diffusion assay may give misleading results. International Society of Ethnopharmacology, Pretoria. Afr. J. Bot., 69, 229.

Ferrazzano, G. F., Cantile, T., Roberto, L., Ingenito, A., Catania, M. R., Roscetto, E., et al., 2015. Determination of the In Vitro and In Vivo antimicrobial activity on salivary Streptococci and Lactobacilli and chemical characterisation of the phenolic content of a Plantago lanceolata infusion. Bio. Med. Res. Inter., 10, 286-817.

Goyal, P., Khanna, A., Chauhan, A., Chauhan, G. and Kaushik, P., 2008. In vitro evaluation of crude extracts of Catharanthusroseus for potential antibacterial activity. Int. J. Green Pharm., 2, 176-181.

Indhumathi, T. and Mohandass, S., 2014. Efficacy of ethanolic extract of solanum incanum fruit extract for its antimicrobial activity. Int. J. Curr. Microbiol. App. Sci., 3, 939-949.

Jiang, L., Wang, F., Han, F., Prinyawiwatkul, W., NO, H. K. and Ge, B., 2012. Evaluation of diffusion and dilution methods to determine the antimicrobial activity of water soluble chitosan derivatives. J. Appl. Microbial., 114, 956-963.

Jorgensen, J.H. and Ferraro, M.J., 2009. Antimicrobial susceptibility testing: A review of general principles and contemporary practices. Clin. Infect. Dis., 49, 1749-1755.

Joshua, M. and Takudzwa, M., 2013. Antibacterial properties of Mangifera indica on Staphylococcus aureus. Afr. J. Cln. Exper. Microbiol., 14, 62-74. 
Kasimala, M. B., Tukue, M. and Ermias, R., 2014. Phytochemical screening and antibacterial activity of two common terrestrial medicinal plants rutachalepensis and rumex nervosus. Bali. Med. J., 3, 166-121.

Khalighi-Sigaroodi, F., Ahvazi, M., Yazdani, D. and Kashefi, M., 2012.Cytotoxicity and antioxidant activity of five plant species of Solanaceae family from Iran. J. Med Plants., 11:43.

Lai, P. K. and Roy, J., 2004. Antimicrobial and chemo preventive properties of herbs and species. Curr. Med. Chem., 11, 1451-1460.

Mukesh, C. and Smita, S., 2010. Parmacognostic and phytochemical screening of Vernonia- amyggalinalinn against selected bacterial strains Middle east. J. sci. Res., 6, 440-444.

Murray, P.R. and Zeitinger, J.R., 1983. Evaluation of Mueller Hinton agar for disc diffusion susceptibility tests. J. Clin. Microbiol., 18, 1269-1271.

Owino, J., Omundi, J. and Ngoci, N.S., 2015. Antibacterial activity of methanolic crude extract of Solanum incanum: Kenyan traditional medicinal plant. Int. J. Scien. Res., 4, 360-563.

Parekh, J., Karathia, N. and Chanda, S., 2006. Evaluation of antibacterial activity and phytochemical analysis of uhina variegate in bark. Afr. J. Biomed. Res., 9, 53-56.

Payyappallimana, U., 2009. Role of traditional medicine in primary health care: An overview of perspectives and challenges in Yokohama. J. Soc. Sci., 14, 723-743.

Schmelzer, G.H. and Gurib-Fakim, A., 2008. Plant resources of tropical Africa (11)1 Medicinal Plant 1. PROTA foundation, Back huys publisher, Wageningen Netherlands, Pp. 459-462.

Singh, A., Bajpai, V., Srivastava, M., RamArya, K. and Kumar, B., 2015. Rapid screening and distribution of bioactive compounds in different parts of Berberispetiolaris using direct analysis in real time mass spectrometry. J. Pharm. Anal., 5, 332-335.

Tapsell, L. C., Hemphill, I., Cobiac, L., Patch, C. S., Sullivan, D. R., Fenech, M., et al., 2006. Health benefits of herbs and species: the past, the present and the future. Med. J. Aust., 185, 54-524. 